\title{
IN PURSUIT OF RELIABLE FLOOD PREDICTION
}

\author{
B.E. VIEUX \& J.E. VIEUX \\ Vieux \& Associates, Inc., Norman Oklahoma, 73072 USA.
}

\begin{abstract}
Flood forecasting necessarily relies on a number of technologies, namely, precipitation measurement at high resolution for large areas; numerical modelling of the hydraulics and hydrology of runoff and routing; and innovative information technology for synthesizing critical information needed for emergency response and risk management. Data sources for precipitation inputs can come from weather radar and automated rain gauges. Regional and urban hydrologic modelling is increasingly based on distributed physics-based hydrologic models that can leverage the high definition rainfall derived from radar and rain gauge measurements. Statistical quality control in real-time is necessary to transform radar-based precipitation estimates into accurate hydrologic model input, which serves as an input to a physics-based distributed runoff model. Geospatial data are necessary for setup and parameterization of such distributed models. Real-time precipitation estimates from radar and rain gauge monitoring are coupled with the gridded representation of the watershed to produce warning notifications at distributed locations throughout urban, peri-urban, and rural/natural watersheds. Quantification of uncertainties and sources of error are examined within the pursuit of successful flood forecasting. The following case studies illustrate distributed hydrologic forecasting across a range of space-time scales. This paper presents forecasting performance, an evaluation of accuracy, and discussion of factors that contribute to uncertainty in flood forecasts and risk reduction.
\end{abstract}

Keywords: flood forecasting, forecast uncertainty, hydrometeorology, inundation mapping, numerical modelling, reservoir operations.

\section{INTRODUCTION}

An approach to reducing flood impacts is to minimize the public's exposure by closing road intersections, or warning residents or businesses to take preventative actions. To provide an effective emergency response, responders must know when and where flooding is likely to occur. This article describes the performance of a flood forecasting system during recent extreme flood events. Public flood warnings are the responsibility of the national meteorological agencies. Increasingly, customized forecasting services are being offered to municipalities, flood control districts, or businesses requiring more specificity in terms of location, timeframe, and type of hydrologic information. Historically, only national governmental agencies had the resources and the ability to perform such services. Vieux and Bedient [1] describe a private-sector flood forecasting system that uses radar and rain gauge input to the finite element model of $260 \mathrm{~km}^{2}$ watershed at 120 -m resolution. It was initiated in 1997 and continues today, providing one of the largest medical centers in the world with required notifications of flooding so that flood defenses can be operated to limit entry of floodwaters into the facilities. Other locations where this approach is being applied operationally include organizations such as a flood control district in the front range of Colorado, municipalities in flash-flood 
alley in Texas, and a hydro-electric plant responsible for power generation and flood mitigation upstream and downstream of a dam.

Enabling technology that makes it possible to offer high-resolution flood forecasts on a commercial basis, includes advances in computing power, information dissemination systems, dual-polarized weather radar, tipping bucket rain gauges or satellite remote sensing technology. Distributed measurement of precipitation at high resolution along with telemetered rain and stream gauge measurements are key elements necessary for the provision of customized high-resolution rainfall-runoff modeling. The web-based services depend on access to real-time weather radar data with hosted computer facilities and high speed internet access. The high-resolution numerical solution to rainfall runoff makes it possible to serve urban flood applications, or for managing reservoir inflow. Within a single distributed framework, it is now possible to provide forecast hydrologic information across a range of time-space scales within the same modeling system. The runoff response resulting in reservoir inflows spanning days across thousands of square kilometers, modeled at 500-m resolution and fifteen-minute time steps. To provide locally specific flood warnings throughout an urban and peri-urban environment, smaller scales are modeled across a range of basin sizes, from less than 30 to over $750 \mathrm{sq}$. km., at 60-m to 500-m resolution.

\section{METHODOLOGICAL APPROACH}

The modeling approach taken relies on numerical solution of the conservation equations governing runoff and routing through overland and channel components of a gridded drainage network. The physics-based distributed model, $\mathrm{V} f \mathrm{o}^{\circledR}$, is setup and parameterized using geospatial data representing terrain, soils, land use/cover, and impervious areas where developed surfaces limit infiltration. The model solves the kinematic wave equations by numerical solution of conservation equations, finite element in space and finite difference in time [2].

1. Model Schema Geospatial data are used to setup the drainage network and parameters. Starting with a digital elevation model (DEM) for the derivation of slope and flow direction (D8); remotely sensed land use/cover for overland hydraulic roughness; impervious area and soil characteristics for derivation of Green and Ampt infiltration parameters and soil depth; channel geometry and hydraulic characteristics.

2. Precipitation Inputs Rainfall and snowmelt may be input on a gridded-basis as maps, or input as uniformly distributed rainfall rates/accumulations. Distributed precipitation can come from NEXRAD radars.

3. Runoff Routing The kinematic wave equations are solved on a grid cell basis within a drainage network composed of finite elements. The formulas are adapted to represent overland and channel hydraulics. Floodplain storage effects can be simulated using the Modified Puls method to account for attenuation due to temporary storage. Complex channel hydraulics are represented by: (1) rating curves for stage area/discharge, (2) surveyed channel cross-sections with slope and Manning's roughness, and (3) trapezoidal cross-sections with slope and Manning's roughness.

4. Soil Moisture and Infiltration The Green and Ampt equation is used to compute infiltration-rate excess runoff in each grid cell as a function of soil properties and antecedent conditions. Once the soil moisture storage capacity is filled, then saturation excess runoff is computed. Soil moisture depletion is limited by the potential evapotranspiration (ET) rate and available soil moisture. 
5. Inundation Mapping Distributed modeling of flow and hydraulic stage supports inundation mapping in two timeframes, (1) post-analysis of flooding extent, and (2) during operational modeling showing maximum inundation forecasts. Inundation maps are produced wherever there are channel cells within the drainage network.

Geospatial datasets are used to setup and parameterize the model, as outlined in [2]. Physical characteristics of the soils, land use/cover, and topography are key sources of distributed parameter maps. Model inputs are derived from radar and gauge precipitation measurements. Evapotranspiration is modeled using measured or climatological rates that are subsequently modified in each grid cell to represent actual conditions, viz. rainfall and available soil moisture. The resulting model has applicability to urban, and natural, and mixed landuse in watershed ranging in scale from headwater catchments to larger rivers. Reservoirs and hydraulic structure operation can be incorporated in the model to represent larger systems. Refinement of model parameters is accomplished using distributed model calibration procedures developed for the desktop edition, described in $[3,4]$.

\section{RESULTS}

The following case studies illustrate principles and application of physics-based distributed hydrologic modeling, which are described in more detail in [2]. These studies illustrate a common theme, namely a customized hydrometeorological system that produces high resolution rainfall derived from radar and rain gauge, and a physics-based distributed model developed using geospatial data, producing hydrologic predictions that span a range of spacetime scales.

\subsection{Case study I - reservoir inflow forecasting}

Operation of a hydroelectric dam can be complicated by many competing objectives, namely business requirements for power generation, respecting downstream environmental releases, as well as, management of lake levels that affect property owners along the impoundment lakeshore. Because of narrow operational constraints, accurate inflow forecasts are paramount. Reservoir inflow is a key component necessary for both power generation, and flood management in upstream impoundment areas, and in downstream river reaches. A customized hydrometeorological network is provided a service, specially configured for the system. It relies on access to the US National Weather Service (NWS), weather radar and rain gauges operated by various federal, state, and local agencies. The forecast system measures current quantitative precipitation estimates (QPE) and ingests numerical weather prediction out to 7-days. Evaluation of sensitivity to model parameters, precipitation, and evapotranspiration forcing is discussed below for two heavy rainfall-runoff events occurring in 2015. Each of these inputs carries uncertainty that contributes to the uncertainty in forecast reservoir inflow, upstream and downstream flooding, and hydroelectric generation.

\subsubsection{Study area}

The Lake of the Ozarks (LOZ) is a reservoir located in Central Missouri on the Osage River covering $222 \mathrm{~km}^{2}$ and storing $2.27 \mathrm{~km}^{3}$. The lake's serpentine shape is apparent in Fig. 1 (dark blue), resulting from impoundment of the Osage River by a dam completed in 1931. Its height is $45 \mathrm{~m}$ tall forming the reservoir comprising a main channel, $151 \mathrm{~km}$ in length from 
a flood control reservoir, Harry S. Truman (HST), connecting downstream to the Dam. The elongated shape and varying depth required finite volume cells for routing flow through shallow water within the inundated body of the reservoir. Releases from HST contributes inflow to the Dam along with runoff from an uncontrolled drainage area from the Niangua River (see labeled drainage network) that drains from south to north, connecting with the LOZs as shown. The uncontrolled drainage area below HST consists of $6,241 \mathrm{~km}^{2}$ (outlined in Fig. 1). The V flo ${ }^{\circledR}$ model of the uncontrolled drainage consists of 25,458 grid cells at 500-m resolution, forming a drainage network comprising both channel and overland flow cells.

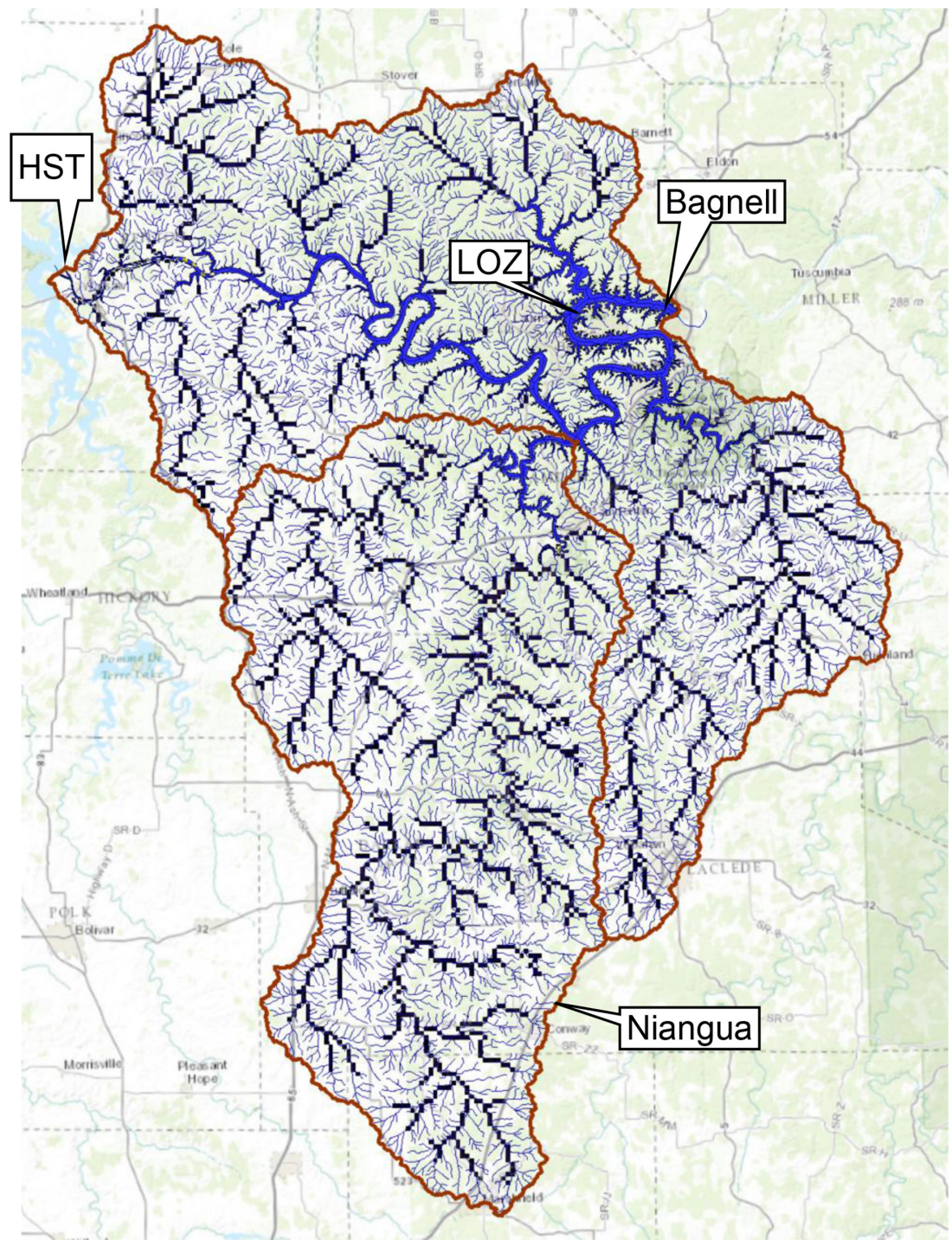

Figure 1: Lake of the Ozarks and tributary drainage area. 


\subsubsection{Forecast objectives}

Forecast services are provided to the dam owner customized for their requirements, relying on a physics-based distributed model of rainfall-runoff, with inputs from current rainfall termed QPE and Quantitative Forecast Precipitation (QPF). Measured evapotranspiration from nine weather stations in and surrounding the basin is used to control soil moisture on a continuous distributed basis across the basin. Besides inflows from uncontrolled drainage areas, lake levels are affected by operational dam releases from the Dam and HST. How much the reservoir level will change in hours, days, or weeks, is important for managing power generation, especially when the lake level rise or downstream discharge impose limits. A continuous physics-based distributed model can be used with advantage to provide knowledge of reservoir inflow from diffuse streams, rivers, combining with discharge from an upstream reservoir. This approach is used to provide reservoir inflow forecasts with input from current and forecast rainfall, uncontrolled watershed runoff, and current or planned releases from the upstream reservoir.

Predicted or forecast reservoir inflow aids in the operation of the dam, provides estimated spill consistent with its operating license, and supports the forecast of lake levels with quantitative precipitation forecasts (QPF) from US NWS, numerical weather prediction at 6-hr intervals out to 7-days. $\mathrm{V} f \mathrm{oo}^{\circledR}$ is at the modeling core of the software system that integrates precipitation and evapotranspiration data for making inflow projections, and supporting webbased delivery of hydrologic information.

\subsubsection{Hydrometeorological system}

Accurate precipitation quantification is necessary for a rainfall-runoff model to yield useful inflow forecasts. Rather than rely on uncertain estimates from the NWS MPE, which is only available from the NWS at hourly and $4 \times 4 \mathrm{~km}$, a high resolution product is operated, which is customized to the target watershed. Three radars are bias corrected and merged to produce gauge adjusted radar rainfall (GARR) at 15 -minute and $2 \times 2 \mathrm{~km}$ resolution for model input. Automated failover from primary to secondary radars, and then to gauge-only gridded rainfall occurs in the unlikely event that all three radars become unavailable. The hydrometeorological system integrates reflectivity from three weather radars (KEAX, KLSX, KSGF), which is bias corrected with rain gauge measurements in real-time.

Soil moisture and infiltration rates are simulated in each grid cell using Green and Ampt parameters for a single layer and soil depth. Thus, both Horton and Dunne runoff components are computed, allowing the infiltration rate and saturation excess to operate simultaneously in the watershed. Soil moisture is depleted at hourly rates by potential evapotranspiration (PET) computed from measured humidity, wind speed, solar radiation, pressure, and temperature. Forecast PET is ingested from the US National Digital Forecast Database, while climatological PET serves as a fallback if data feeds of current measurements or forecast PET are unavailable in operations. Operation of the dam requires reasonably accurate continuous simulation across a range of runoff events from small to large.

\subsubsection{Forecast performance}

In order to create a detailed model of the watershed capable of modeling the often highly variable response to soil moisture and rainfall distributions, a gridded model is setup that leverages geospatial data available across the US. Geospatial data availability means distributed models can incorporate information from maps of land use or vegetative cover, complex terrain, and soils to make the needed predictions of rainfall-runoff. When rainfall 
derived from weather radar and rain gauges is properly controlled for accuracy, it can be used as a necessary ingredient for operational modeling of the watershed. Model calibration is used to fine-tune the model to be more accurate using historical rainfall data. Review of the model performance from operational review provides insight into how the system can be improved when there is a trend in over- or under-prediction. The information system that manages the rainfall production, modeling, and data/information display and interconnections are tailored to provide the specific requirements for forecasting reservoir inflows. An example of forecast lake level based on current and forecast rainfall is presented in Fig. 2 for a high flow period in July, 2015. The three forecast lines (green, blue, and red) represent lake level response to forecast precipitation at 90, 50, and $10 \%$ exceedance probabilities, respectively. Observed lake level is shown as blue circles to the left of the 'Now' line at 9:01 on July 1, which are used to initiate the forecast in each 6-hr update period.

Continuous simulation with measured PET results in optimization of the model where adjustments to saturated hydraulic conductivity, $K_{\text {sat }}$, and Soil Depth, $S_{d}$, help achieve minimization of the Nash Sutcliffe and mean absolute percentage error (MAPE). Model response was tested is for a range of multipliers applied to distributed maps of each parameter, namely, $K_{\text {sat }}$ and $S_{d}$. For continuous simulation starting January 1, optimal results are achieved with multipliers of $K_{\text {sat }} \times 0.3$ and $S_{d} \times 1.3$. The result is that $K_{\text {sat }}=1.09 \mathrm{~cm} / \mathrm{h}$ is reduced to $0.43 \mathrm{~cm} / \mathrm{h}$, and $S_{d}$ increases from 63.5 to $82.6 \mathrm{~cm}$. PET can be formulated by several methods including climatological values or measured atmospheric parameters using the ASCE reference ET method (Walter et al. 2000). In Fig. 3, hydrographs produced with three PET inputs for climatological PET, measured PET with crop coefficients, Kc.

\section{Lake of the Ozarks, Bagnell Dam}

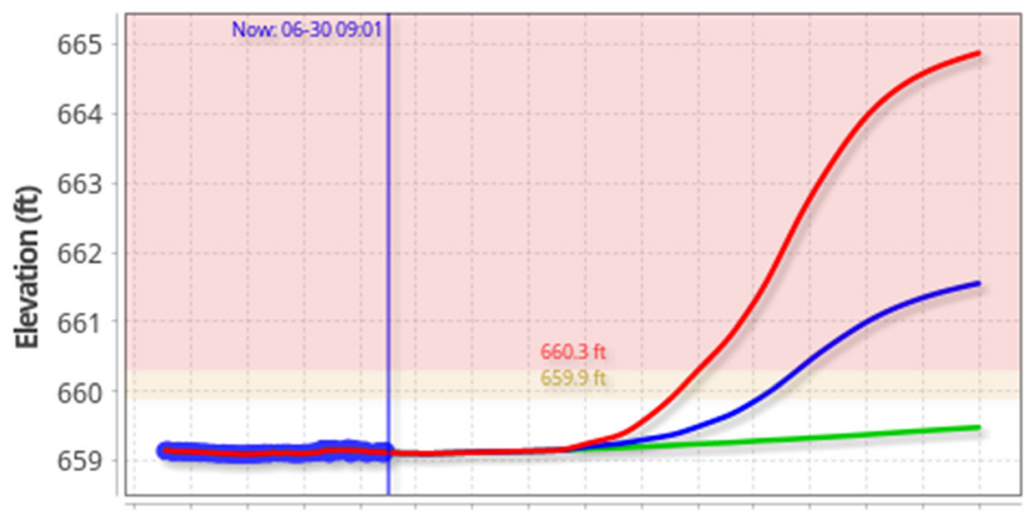

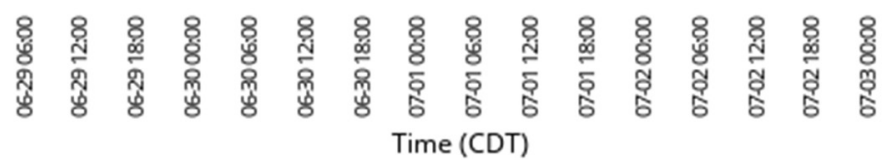

\footnotetext{
- Simulated Elevation (10\%) - Simulated Elevation (50\%)

- Simulated Elevation (90\%) ○ Observed Elevation
}

Figure 2: Lake level forecasts $(1.0 \mathrm{ft} .=0.3048 \mathrm{~m})$. 


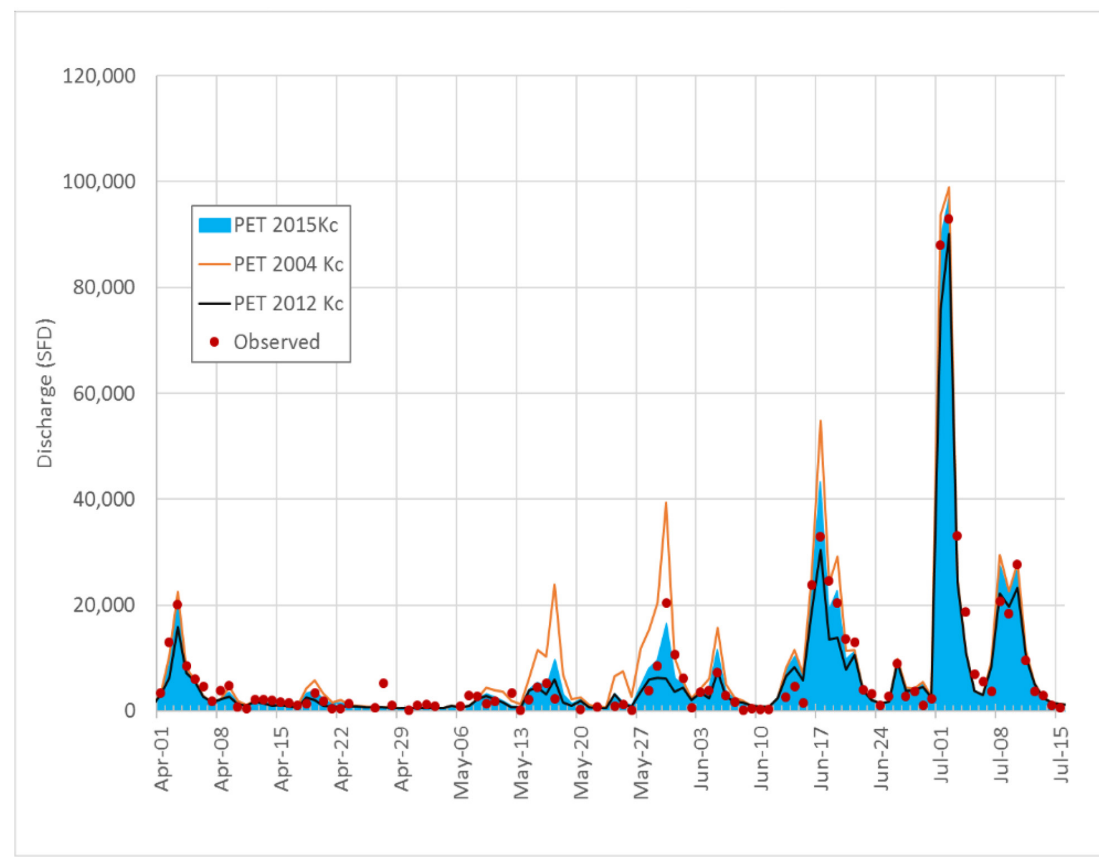

Figure 3: Sensitivity to PET by continuous simulation during. (35.31 SFD $=1 \mathrm{~m}^{3} \mathrm{~s}^{-1} \cdot$ day).

These simulations are 'hindcasts' used to evaluate PET inputs, and for identification of optimal parameter sets.

\subsection{Case study II - urban flood forecasting}

Operational flood forecasting of urban basins is presented for recent floods in 2015 and 2016. The forecast system is operated as a service for the municipality, providing flood stage and inundation within a distributed model framework across urban, peri-urban and natural watersheds. Emergency operation personnel have detailed, "actionable" information about flooded buildings, streets, and low water crossings for coordination of emergency response. Analysis and review of model forecasts in relation to observed stream stage reveals that QPFs improve lead time in flood warning and emergency response [3].

\subsubsection{Study area}

Geographic location near the Gulf of Mexico and terrain typical of the Texas Hill Country results in fast-moving runoff during heavy rainfall, creating dangerous conditions and flash flooding in a growing urban and peri-urban environment. Because of the tremendous runoff potential, central Texas is one of the most flash-flood prone regions in North America, earning the nickname, "Flash Flood Alley." Better rainfall data and flood prediction information available in near real-time allows for a faster, more targeted response to heavy rainfall, which means more time to close roads, reroute traffic, activate high-water signals and deploy emergency personnel before an impending flood. To achieve this goal, both accurate rainfall and model forecasts are provided in a web-based framework to help protect the public from flood hazards posed by stream flooding and twelve high hazard dams. 


\subsubsection{Forecast objective}

Early warning of flooding is an important public safety issue for a city in central Texas. The municipality takes actions to help protect its citizens from food risks. An historical event, motivated the formation of the city's flood early warning system in May (Memorial Day) of 1981 that killed 13 people. In response, the city deployed four telemetered rain gauges. Since then, new technologies were implemented in rainfall monitoring and hydrologic prediction that have proved useful in emergency response to flooding caused by urban stormwater. Rainfall can be highly variable in space and time, making it difficult to characterize accurately over a watershed. Spatially distributed rainfall and physics-based, distributed hydrologic modeling offer high-resolution information for real-time emergency management and response.

Radar rainfall is a powerful tool for hydrologic prediction because it captures the spatial and temporal variability of rainfall as it occurs over watersheds. In recent years, considerable attention has been focused on radar hydrology and its quantitative application in hydraulic and hydrologic modeling, as opposed to weather radar used alone merely as a meteorological indicator of precipitation intensity. Application of radar-derived rainfall in urban drainage modeling is described by $[1,2,5,6]$.

Rainfall monitoring consists of a hydrometeorological system customized to provide realtime model inputs for flood forecasting and inundation mapping. The rainfall used in real-time distributed hydrologic modeling consists of radar at $1-\mathrm{km}$ resolution and rain gauges surrounding the target watersheds. The $4,483 \mathrm{~km}^{2}(1 \times 1 \mathrm{~km}$ pixels $)$ study area covering the city's watersheds is served by two S-band NEXRAD (WSR-88D) radars. Radar reflectivity is converted to rainfall rate by means of a default Z-R relationship, and then updated continuously through a bias correction in real-time using rain gauge accumulations, with updates every 15 minutes. Through data sharing, gauge data from adjacent networks operated by other governmental entities are incorporated to begin the bias adjustment before rainfall moves into the area.

The capability of radar to provide accurate rainfall estimates over large areas at high resolution has the potential to provide needed rainfall model inputs for inundation forecasts and custom flood alert systems. The WSR-88D radar deployed by US NWS is an S-band radar with a $10-\mathrm{cm}$ wavelength, which can penetrate rainfall with little attenuation out to $230 \mathrm{~km}$ in range from the radar [5]. This feature is especially useful for covering large areas where there is a little blockage from terrain or other obstructions. The hydrometeorological system is tailored to the flood forecasting objectives of the municipality. In the online mode, the system ingests radar and rain gauge data and stores in a database with controls for data quality that rejects outliers, corrects for bias, and tracks statistical accuracy. The recent addition of dual polarization to NEXRAD radars results in a QPE product called Digital Precipitation Rate (DPR) is independent of rain gauges. The performance of the radar rainfall versus rain gauge input, and its influence on forecast lead time and accuracy, is described in [6]. Reservoir inflow forecast sensitivity to radar-derived inputs and to soil moisture is evaluated and described in [7].

\subsubsection{Forecast inundation}

One of the main forecast objectives is a mapping of inundation, with depth rasters showing affected buildings and bridges. The inundation maps are generated on a gridded basis that relies on the definition of the flow direction map extracted from a high-resolution is necessary for mapping stage files produced at the model-grid resolution. A high-resolution flood inundation map from recent flooding is shown in Fig. 4. These maps provide emergency 


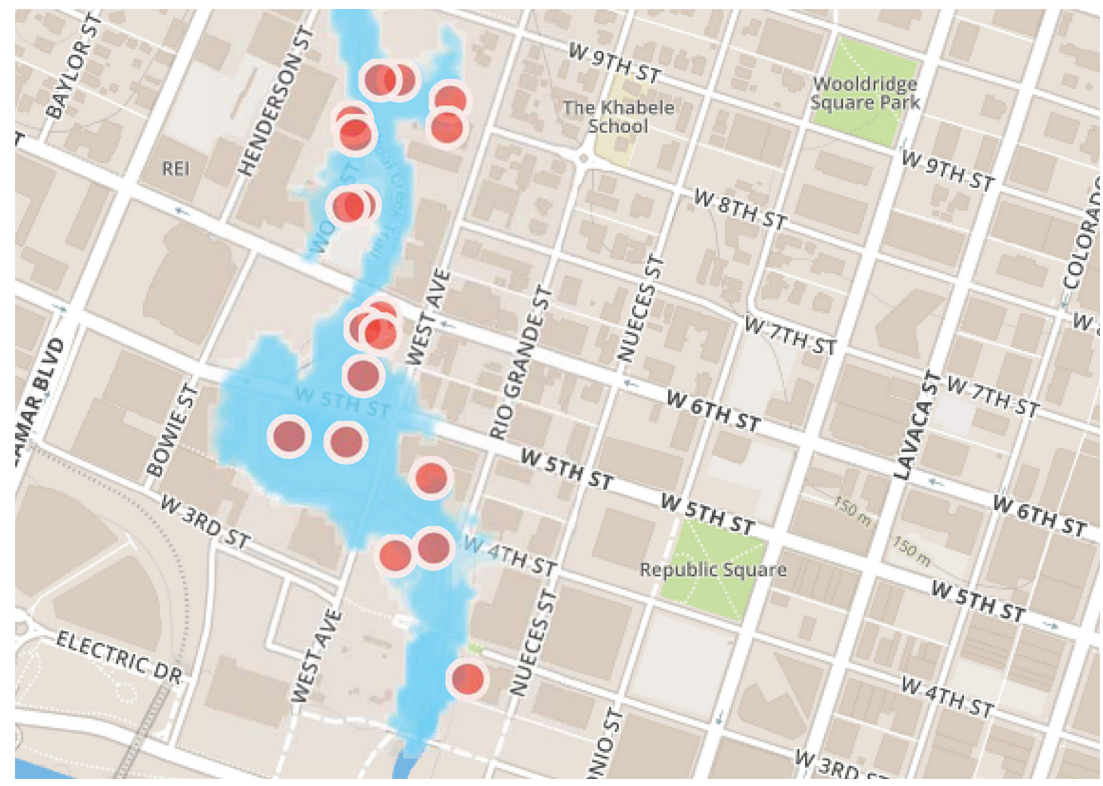

Figure 4: Inundation depth mapping (blue shaded) and flooded structures (red dots).

management personnel with specific locations of flooded structures, and are used for evacuation and barricading of impacted roads.

\subsubsection{Forecast uncertainty}

An example of a flood forecast hydrograph is shown in Fig. 5, the basin response to copious rainfall amounts, exceeding $355 \mathrm{~mm}$ during a 6-hr period (see band of red pixels). Rainfall intensity in some pixels exceeded $235 \mathrm{~mm} / \mathrm{h}$ in a 15 -min period. These broadly distributed rainfall depths and intensities measured by GARR and DPR in real-time, drove the observed and modeled hydrograph peak response under 6 hours. Both GARR and DPR forecast hydrographs are in close agreement with observed stage, to within $30 \mathrm{~cm}$ in peak stage.

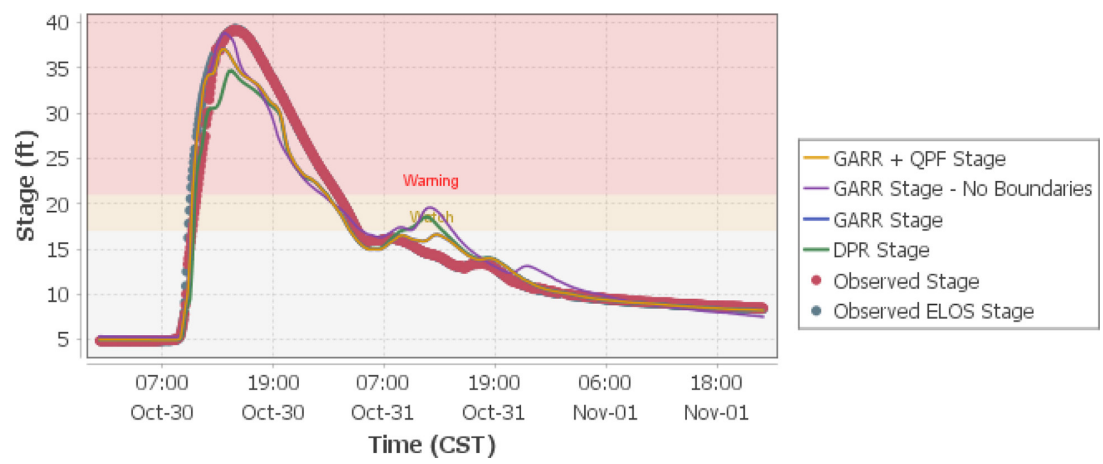

Figure 5: Operational forecasting results during the October 31, 2015 flood in Central Texas. $(1 \mathrm{ft} .=0.3048 \mathrm{~m})$. 
Because this region experiences intense but highly variable rainfall, significant flooding at multiple locations occurs throughout the urban and peri-urban areas. The QPE is produced at high temporal resolution for input with basins, many of which respond in less than an hour. Real-time operation produces hydrographs that have sufficient lead-time for the emergency response staff to make decisions and take actions during immediate flood threats.

\subsection{Forecast uncertainty}

Quantification of uncertainties and sources of error are important for understanding forecast reliability in both case studies dealing with reservoir inflow and urban flood forecasting. Sources of error in distributed hydrologic forecasting include an error in current rainfall, QPE, and in forecast rainfall, QPF. As with any modeling approach, the structure of the model can introduce important biases in runoff predictions from a given input. Two runoff mechanisms operate simultaneously throughout the basin, namely infiltration rate excess and saturation excess, thus making accuracy in rainfall depth and rate of paramount importance. Soil moisture can only be interpreted indirectly through modeling of PET from atmospheric measurements, and applied to variable soil profiles across a range of spatial and temporal scales. Continuous simulation using measured PET, as opposed to climatological PET, revealed that model performance could be improved. Recalibration of soil parameters was necessary, once measured evapotranspiration rates were incorporated into the analysis, accomplished using scalar adjustments. Precipitation accuracy is controlled operationally but the hydrometeorological system using rain gauges to adjust radar-based QPE. Accuracy of this product is controlled by the timely ingest of rain gauge data, and the number and distribution of correctly functioning rain gauges across the forecast domain.

\section{SUMMARY}

In the pursuit of reliable flood forecasting, multiple technologies must be harnessed. Precipitation measurement at high resolution for large areas must be configured to generate accurate and reliable precipitation model inputs. The hydrometeorological system used to generate hydrologic model input should provide rainfall distributions that are representative over the watershed. Various methods have been developed to enhance the accuracy of radar rainfall estimates, most of which rely on rain gauge accumulations to adjust the bias inherent in radar measurements. Hydrologic prediction accuracy is directly tied to the accuracy of rainfall measurements distributed over the target watershed. With accurate inputs, it is possible to accurately model the hydraulics and hydrology of runoff, and route the resulting streamflow downstream in the drainage network. Modeled output is formulated for interpretation and use as inundation maps and for warning at critical stream crossings. Reservoir inflow forecasts and urban flood forecasting depend on accurately characterizing soil moisture and rainfall rates, while the model structure effectively represents the runoff processes as demonstrated for basin scales with short and long response times ranging in size from less than $30 \mathrm{~km}^{2}$ to over $6,000 \mathrm{~km}^{2}$ at model resolutions ranging from $60-\mathrm{m}$ to $500-\mathrm{m}$ model resolution.

\section{REFERENCES}

[1] Vieux, B.E. \& Bedient, P.B., Assessing urban hydrologic prediction accuracy through event reconstruction. Journal of Hydrolofy, 299(3-4), pp. 217-236, 2004. http://dx.doi.org/10.1016/S0022-1694(04)00366-X 
[2] Vieux, B.E. Distributed Hydrologic Modeling Using GIS, 3rd edn, Springer, forthcoming, 2016.

[3] Vieux, B.E. \& Moreda, F.G., Ordered physics-based parameter adjustment of a distributed model. Calibration of Watershed Models, pp. 267-281, 2003. http://dx.doi.org/10.1029/ws006p0267

[4] $\mathrm{V} f l o^{\circledR}$ User Manual, available at: http://vflo.vieuxinc.com/vflo-guide, (accessed May 2016).

[5] Bedient, P.B., Huber, W.C. \& Vieux, B.E., Hydrology and Floodplain Analysis. 4th edn, Prentice-Hall: Upper Saddle River, NJ, 2013.

[6] Looper, J.P. \& Vieux, B.E., An assessment of distributed flash flood forecasting accuracy using radar and rain gauge input for a physics-based distributed hydrologic model. Jouranl of Hydrology. 412, pp. 114-132, 2012.

http://dx.doi.org/10.1016/j.jhydrol.2011.05.046

[7] Vieux, B.E., Kang, B., Park, J.H., On distributed hydrologic prediction: sensitivity to accuracy of initial soil moisture conditions and radar rainfall input. Journal of Hydrologic Engineering, 14(7), pp. 671-689, 2009.

http://dx.doi.org/10.1061/(ASCE)HE.1943-5584.0000039 